\title{
Wistful thinking
}

\section{William R Muirhead}

I was recently lucky enough to attend a talk at the Royal College of Surgeons about women in surgery. As it happens, I have no plans to become a woman in surgery (although at this stage of my career I think it's too early to rule anything out completely) and I found myself in the audience through politeness rather than choice. The speaker was a very prominent female surgeon and, as far as I could tell, wanted to get across three main points: first, the national organisation WiST (Women in Surgical Training) has been rebranded as WinS (Women in Surgery) and that this is a much better, less wistful and more appropriate acronym; second, women frequently make excellent surgeons, are now widely accepted in the profession, and are as good as, if not better than, their male counterparts (apart from anything else they are inarguably better communicators); and finally, despite the fact that $65 \%$ of medical students are now female, the vast majority of applicants for surgical training remain male and that this is a very puzzling state of affairs.

While this may be uncontroversial bread-and-butter stuff regularly repeated up and down the country, I don't agree that it's puzzling at all. A century after Emmeline Pankhurst's hunger strikes, we are apparently keener than ever to characterise and explain the perceived differences between men and women. The orthodox view that these are socially constructed is increasingly being supplanted by the idea that men and women are somehow 'hard-wired' differently. In the early 1990s we discovered that men are in fact from Mars, but we now have a Cambridge professor of psychopathology telling us: "The female brain is predominantly hard-wired for empathy. The male brain is predominantly hard-wired for understanding and building systems."1

A short trawl through Amazon reveals that it would be perfectly possible to fill a small library entirely with books

Correspondence to Dr Will Muirhead, The Queen's Medical Centre, Nottingham University Hospitals NHS Trust, Derby Road Nottingham, NG7 2UH, UK; will.muirhead@nhs.net purporting to catalogue the fundamental psychological differences between boys and girls. By volume if nothing else, the largest contributors look to be the self help, power couple Allan and Barbara Pease, whose previous careers as a door-todoor salesman and model, respectively, have left them uniquely qualified to author, among other titles: Why Men Can Only Do One Thing at a Time and Women Never Stop Talking, Why Men Don't Have a Clue and Women Always Need More Shoes, Why Men Lie and Women Cry, Why He's So Last Minute and She's Got It All Wrapped Up, and Why Men Don't Listen and Women Can't Read Maps. Even Channel 4 has jumped on board with Why Men Don't Iron-a TV show which argues that differences in brain structure ensure that men are forever destined to be terrible communicators and women poor at parallel parking.

The reality is, gender stereotypes pervade every aspect of our lives and are perpetuated by everyone who has ever bought a little boy an action man or dressed their daughter in pink (as an interesting aside-until the 1940s pink was thought to be more appropriate for boys and blue for girls). ${ }^{2}$ There is a powerful argument advocated by contemporary feminists that it is the psychological constraints generated by these stereotypes that are the real obstacles to sexual equality: while society's official attitudes have ostensibly been transformed over the previous century, our casual assumptions about the abilities and responsibilities men and women should aspire towards, in both their work and home lives, have changed little. ${ }^{3}$

And here's the rub: if we buy into (as apparently many of us do) the Pease family fantasy, then specialties like surgery quite clearly sit more naturally with the male rather than the female archetype. In this day and age, no-one is going to claim that surgeons can be wholly unempathetic, but compared to medical oncologists the emphasis of skills required is undeniably different. No amount of surgical rebranding is going to get away from the fact that surgeons are required to stand in relative silence for hours at a time, often underground, manipulating tools in three dimensional space. I struggle to think of a more suitable activity for Channel 4's macho stereotype; what after all could be a more typically male preserve than video gaming, and yet we are led to believe that surgery will look more and more like playing X-box. Video gaming performance has even been shown to correlate with performance on surgical simulators. ${ }^{4}$ It is surely just a matter of time before the Peases catch on and Why Women Break Bad News and Men Fix Fractures flies onto our shelves.

Here's what's really sad: these presumptions become self fulfilling and positive stereotypes can be just as destructive as negative ones. Most people are not polymaths and it is easy to reason that strength in one area will be matched by a relative weakness in another: we lazily presume quantum physicists will be rubbish at Keepie Uppie just as we imagine Premiership footballers will not qualify for Mensa. As it happens, Frank Lampard is reported to have a higher IO than Carol Vorderman. ${ }^{5}$

People like to play to their strengths; if we raise girls to believe that purely by being girls their strengths lie in social interaction, then surely they will turn into junior doctors who gravitate towards careers which maximise their opportunity to use this self perceived strength. Conversely, if we tell little boys (implicitly or explicitly) that purely by being boys they lack 'female intuition' and are at an inherent disadvantage at nuanced, sensitive social interactions, then we can surely not be surprised if they grow up into junior doctors who opt for careers that emphasise a different skill set.

In the women's favour, it is at least considered rather unevolved to snicker when they opt for a career that does not sit naturally with society's expectations of their abilities. The men have no such luxury-for a striking example look at the stigma some people still attach to being a male nurse, or as some female doctor friends of mine cruelly abbreviate, a 'murse' (it rhymes with 'purse'). The whole joke hinges around the apparent incongruity of a man in a career that is heavily reliant on the stereotypically female traits of being caring and emotive.

Only the very cynical (or very misogynistic) could dispute that organisations like WinS do valuable work. But they can only ever be a small part of the puzzle. If we are genuinely interested in a more uniform gender distribution across medicine, then we need to address a problem which is greater than any one specialty, 
greater in fact than the profession itself, and address the superficially innocuous stereotypes that are much more prevalent and influential than we commonly admit.

Competing interests None declared.

Provenance and peer review Commissioned; not externally peer reviewed.
Postgrad Med J 2011;87:160-161.

doi:10.1136/pgmj.2011.117341

\section{REFERENCES}

1. Baron-Cohen S. The Essential Difference: Male and Female Brains and the Truth About Autism. New York: Basic Books, 2003.

2. Kidwell CB, Steele V. Men and Women - Dressing the Part. Washington: Smithsonian Institute Press, 1989.
3. Walter N. Living Dolls: The Return of Sexism. London: Virago, 2010.

4. Lynch J, Aughwane P, Hammond TM. Video games and surgical ability: a literature review. J Surg Educ 2010;67:184-9.

5. Celebrity News. Frank Lampard 'has higher 10 than Carol Vorderman'. The Telegraph [online], 2009. http:// www.telegraph.co.uk/news/newstopics/celebritynews/ 4940708/Frank-Lampard-has-higher-IQ-than-CarolVorderman.html (accessed 26 January 2011).

\section{Corrections}

Medford A, Maskell N. Pleural effusion. Postgrad Med J 2005;81:702-10. In this paper the middle initial of the first author's name is missing and should be Medford AR.

Postgrad Med J 2011;87:161. doi:10.1136/pgmj.2005.035352corr1

Robins GG, Sarwar MS, Armstrong M, et al. Evaluation of the need for endoscopy to identify low-risk patients presenting with an acute upper gastrointestinal bleed suitable for early discharge. Postgrad Med J 2007;83:768-72. In this paper the middle initial of the third author's name is missing and should be Armstrong MJ.

Postgrad Med J 2011;87:161. doi:10.1136/pgmj.2007.061614corr1 